\title{
Santiago Navarro de la Fuente, La Santa Sede y la Guerra Civil. Los representantes del Papa en la España en conflicto (1936-1938), Sevilla, Editorial Universidad de Sevilla, 2019, 653 pp.
}

El libro que hoy recensionamos es el fruto de varios años de estudio y reflexión de nuestro amigo e investigador, el doctor Santiago Navarro de la Fuente. El trabajo, como su propio autor indica, "ha sido finalmente articulado en torno a tres grandes periodos, que se relacionan con cada una de las misiones diplomáticas estudiadas. No obstante, los límites han sido lo suficientemente flexibles como para integrar en alguna ocasión el contenido que, aun excediendo los límites cronológicos que los distinguen, resulta más oportuno incluir en cada uno de los bloques" (p. 21).

Tras el prólogo del doctor José-Leonardo Ruiz Sánchez, catedrático de Historia Contemporánea de la Universidad Sevilla y director de la tesis doctoral de Santiago Navarro, el autor, en una breve introducción, nos comenta la génesis y recorrido de su trabajo a partir de la documentación consultada en los siguientes archivos: Secreto Vaticano (hoy Apostólico por decisión del papa Francisco), de la Embajada Española ante la Santa Sede, de la Sagrada Congregación de los Asuntos Eclesiásticos Extraordinarios, del Ministerio de Asuntos Exteriores de Italia, de la Archidiócesis de París, de la Nunciatura de Madrid.

El libro se vertebra en tres partes. La primera está dedicada a la época y figura de Silvio Sericano, encargado de negocios en vísperas de la sublevación militar, ya que el cardenal Federico Tedeschini, nuncio desde 1921 hasta junio de 1936, para ser sustituido por Filippo Cortesi. Desde ese momento, la representación del papa en España asumió un carácter provisional hasta junio de 1938. Esta primera parte consta de tres capítulos. El primero, Silvio Sericano, encargado de negocios en vísperas de la sublevación militar (11 de junio - 13 de julio 1936), analiza los cinco apartados siguientes: las relaciones entre la Santa Sede y España a la marcha de Tedeschini; el nuncio se marcha - y se hace cargo Sericano-; los informes a Roma; las protestas ante el Gobierno; las relaciones con los obispos. El segundo capítulo, Las gestiones en la Nunciatura durante los primeros meses de la Guerra (13 de julio -4 de noviembre de 1936), estudia los siguientes aspectos: las vísperas de la Guerra Civil; el Gobierno de Giral (19 de julio al 4 de septiembre de 1936); el Gobierno de Largo Caballero (4 de septiembre al 4 de noviembre de 1936); la postura de la Santa Sede; la Guerra en las cancillerías; otros aspectos; la partida de Silvio Sericano el 4 de noviembre de 1936. El capítulo tercero, el último de esta primera parte, El otoño romano de 1936 (septiembre - diciembre de 1936), reflexiona sobre: dos gobiernos ante la Santa Sede; Gomá en Roma.

La segunda parte de este libro se centra en la figura del cardenal Isidro Gomá en el periodo comprendido entre diciembre de 1936 a julio de 1937; 
pp. 188-320). Consta también de tres capítulos. El primero —o cuarto en el libro-, Gomá, representante oficioso (19 de diciembre de 1936 - 21 de julio de 1937), estudia los siguientes puntos: el establecimiento del "status quo"; el ritmo de las reformas; la cuestión del clero castrense; la conquista de Málaga; la naturaleza del"Movimiento"; el problema del reconocimiento romano; La "Pascua de las tres encíclicas"; la Carta Colectiva del episcopado español; el final de la misión. El capítulo segundo —o quinto-, La "Cuestión Vasca" (19 de diciembre de 1936 al 21 de julio de 1937), analiza los siguientes aspectos: los nacionalistas vascos ante la Guerra; los planteamientos de Gomá en Roma; la condena del nacionalismo vasco; la intercesión pontificia en la toma de Bilbao; la situación del clero; los planteamientos del obispo Múgica. El tercero capítulo - o sexto del libro-, La situación de la Nunciatura (4 de noviembre de 1936 al 3 de enero de 1939), analiza los siguientes aspectos: tras la marcha de Sericano; el intento de "pasar" al encargado de negocios a la "zona nacional"; las cartas del padre Ariz; un "depósito de armas"; la asistencia al personal en Madrid.

La tercera y última parte del libro, Ildebrando Antoniutti (julio de 1937junio de 1938; pp. 323-561), es la más extensa y consta, también, de tres capítulos. En el primero - séptimo del libro- quedan reflejadas las siguientes cuestiones: el momento del encargo; el envío a España; los asuntos pendientes; la preocupación por la influencia nazi; las informaciones a la Secretaría de Estado. El capítulo segundo - octavo-, Antoniutti, encargado de negocios ante el Gobierno de Franco (7 de octubre de 1937 - 18 de junio de 1938), profundiza en los siguientes puntos: la entrega de credenciales; las audiencias con Franco; el nuevo Estado; contra la influencia nazi; la reversión de la legalidad republicana; el problema vasco; las intercesiones del Pontífice; gestiones con Gomá; los sacerdotes en el frente; las querellas internas del clero regular; el intento de armisticio. El capítulo tercero —noveno y último del libro-, La misión de Antoniutti más allá de la Diplomacia, recoge los siguientes aspectos: la repatriación de los niños vascos; las cuentas; una Iglesia para después de la Guerra; Antoniutti y la"otra Iglesia"; el final de la misión de Antoniutti.

Santiago Navarro de la Fuente, después de ofrecer en estos nueve capítulos los temas centrales de su tesis doctoral, brinda, como punto final de su extenso libro, unas Conclusiones (pp. 563-572). En relación a la figura y papel de Sericano, concluye: que era "un hombre adecuado para el momento que ya no existía puesto que ni el Gobierno parecía tener la voluntad o capacidad de hacer valer los derechos de los católicos, ni los obispos españoles quisieron renunciar a la oportunidad que la sublevación les ofrecía para desmantelar la República" (pp. 564-565). Por otra parte, sobre Gomá manifiesta que el cardenal"insistió siempre que Franco era merecedor de toda confianza, garante de la catolicidad de la nueva España... y como un animador de la catolicidad del militar para que no desfalleciera en el propósito 
de dar a la Iglesia una preponderancia social conforme a la tradición del país y contraria a la situación hostil creada por la República" (p. 565). Por último, la labor de Antoniutti se centró en la cuestión vasca: intercesión por los curas vascos acusados de nacionalismo y ayuda y repatriación de los niños vascos enviados al extranjero. El acercamiento de Antoniutti a la España de Franco fue progresivo y su"misión fue entonces la de ir influyendo en el Estado que estaba construyéndose de forma que se fuera neutralizando la influencia nazi que tanto temían en la Santa Sede y que se fuese promulgando una ordenación en todo conforme a la doctrina de la Iglesia" (p. 566). Para el autor, en su conjunto, "las tres representaciones provisionales de la Santa Sede en España en guerra suponen una evolución clara en la extinción de las relaciones con la España republicana y la articulación y consolidación de estas con la España de Franco"' (p. 567).

Después de la Bibliografía (pp. 573-580) y Fuentes Archivísticas (pp. 581582), Navarro de la Fuente nos ofrece cuatro anexos (pp. 583-646): informe de los desmanes antirreligiosos cometidos del 1 de abril al 20 de junio de 1936; protesta por la prohibición del culto y asistencia religiosa en muchos pueblos, de 15 de julio de 1936; carta de dimisión de Mateo Múgica; carta personal de Mateo Múgica a Pacelli con ocasión de su dimisión. Finaliza con un índice onomástico (pp. 647-653).

En definitiva, se trata de un cuidado y excelente libro que refleja el papel jugado por el gobierno de la Iglesia en su nivel más alto durante el conflicto español, estudiándolo a través de su representación diplomática provisional entre 1936 y 1938: Silvio Sericano, el cardenal Isidro Gomá e Ildebrando Antoniutti. Nuestro amigo Santiago Navarro ha buscado y, a nuestro humilde parecer lo ha conseguido con creces, la explicación más global posible sobre el alcance de las tres misiones estudiadas, juntamente con las acciones caritativas, la gestión económica y los aspectos relacionados con la vida cotidiana. Felicitamos a Santiago Navarro, felicitación que hacemos extensiva a su director de tesis, José-Leonardo Ruiz Sánchez, catedrático de Historia Contemporánea de la Universidad de Sevilla, nuestro amigo y compañero de la Cátedra"Beato Marcelo Spínola". Y nuestro agradecimiento y felicitación a la Editorial Universidad de Sevilla que lo ha hecho posible.

Manuel Martín Riego Facultad de Teología San Isidoro de Sevilla mmartin@ceuandalucia.es 


\section{Juan Del Río Martín, Nuevos apuntes para la vida (Colec. Popular 242), Madrid, BAC, 2019, 465 pp.}

Este libro, como señala el título, son apuntes "nuevos", pues ya el autor publicó en su día otro repertorio de escritos semejantes, redactados en los primeros tiempos de su ministerio episcopal. Ahora da a la luz otra cosecha, fruto de sus constantes esfuerzos de estudio y reflexión durante el 2006 y el 2018. Y es que, por formación y convicción, en el ejercicio de su servicio pastoral, el Prelado ama comunicar, compartir ideas, propagar entusiasmo, dejar constancia de sus vivencias y perplejidades. Y esto no por estrategia humana sino por vocación evangelizadora. Este libro es una preclara muestra de ese espíritu misionero, que lo lleva con asiduidad a esparcir copiosamente la semilla del Evangelio, para que aquellos que tiene encomendados a su cuidado apostólico se adentren de su mano en el Corazón de Dios y en la hondura humana, no queden a oscuras en las arduas cavidades de las elecciones personales y sean pujante levadura en el meollo de las encrucijadas sociales.

Esta publicación recoge 216 breves e incisivas consideraciones, espigadas entre otras muchas redactadas por el Arzobispo Castrense de España, por Don Luis Manuel Romero Sánchez, Director del Secretariado de la Comisión Episcopal de Apostolado seglar de la Conferencia Episcopal Española, que asimismo se ha encargado del prólogo del volumen, vertebrando y agrupando también las temáticas de esta obra en tres grandes bloques: vida cristiana; año litúrgico y jornadas eclesiales; iglesia y sociedad.

Estas páginas no son un alarde de abstracción ni dan pábulo a piruetas teóricas. Están más bien tejidas con hechos concretos de la vida diaria, al hilo de noticias cotidianas o de eventos precisos, sobre los que vale la pena detenerse para sopesarlos, en un ejercicio de lúcido discernimiento. Tienen su cuna, por consiguiente, en el quehacer pastoral del Prelado, que tanto en su primera sede, Jerez de la Frontera, como ahora al frente del Ordinariato Militar de España, ha multiplicado sus intervenciones escritas para ofrecer puntualmente a su grey claridad y criterios para comprender desde el Evangelio las cuestiones candentes que surgen con el pasar de los días. Son apuntes hilvanados con cordialidad y amplitud de miras, para dejar constancia con frecuencia de sucesos universales, pero no solo. El Prelado vierte su luz también en jalones de la intrahistoria, en esos hitos minúsculos, pero que de ordinario condicionan o están en la raíz de giros sociales o eclesiales de mayor envergadura. Con sus escritos lo que en realidad pretende el autor es sembrar esperanza en los corazones atribulados; dar respuesta a las nobles inquietudes que anidan en el alma humana; reiterar los grandes principios de la doctrina social de la Iglesia; deshacer entuertos; avivar el buen humor en medio de una sociedad que a menudo está encarcelada en el pesimismo. Se subraya de esta manera, y me parece que puede ser la condensación de 
estas páginas, la firme voluntad del Arzobispo de proponer la Buena Noticia de Jesucristo como quicio para una existencia humana con sentido y una sociedad hija de la paz, la justicia y la solidaridad.

Cuando toma la pluma, el autor adereza sus escritos no solo con amplias dosis de espontaneidad y sentido común, sino también con citas acrisoladas al calor de la sabiduría bíblica, popular y teológica. Usa, sobre todo, abundantes ideas del magisterio papal, traído a colación con tino y agudeza para mostrar que el gran tesoro de la Iglesia es la comunión. Efectivamente, con Pedro y bajo Pedro, el cristiano anda por caminos seguros, encontrando en la palabra del Obispo de Roma acicate y bálsamo para afrontar las problemáticas cotidianas con acierto y humildad.

En un mundo de prisas y multiplicidad de compromisos, un libro como el que nos ocupa es ideal para tomarlo como compañero. Sus capítulos enjundiosos lo permiten, teniendo la extensión adecuada para no cansar. Antes bien, cada uno de ellos aviva la sed del lector para que continúe avanzando en la lectura.Y, al respecto, se nota que el autor está versado en el mundo de la prensa, caracterizándose el despliegue de su pensamiento por un estilo vivaz y no alambicado, rico de matices y, al mismo tiempo, amante de la frescura y la sencillez, con frases certeras, yuxtapuestas y breves, muy en el estilo de Azorín. Todos estos ingredientes anclan el pensamiento de Mons. Del Río a las aspiraciones de quien recorre estas páginas con ansias de aprender.

En la primera parte de este volumen, como arriba asentado, se recolectan apuntes del Prelado sobre cuestiones cotidianas, surgidas del correr de los días, y que abarcan temáticas familiares o problemáticas personales. El autor se detiene en virtudes y vicios, retos e inercias, flaquezas y proezas humanas. Cuando se adentra en una vertiente, el Arzobispo lo hace buscando poner de manifiesto lo que construye y beneficia, sin caer en el tono gris que no pocas veces embarga nuestras vidas y nos impide aspirar a la excelencia y la positividad.

La segunda parte de este libro ofrece claves para vivir con auténtico sentido eclesial momentos álgidos del año litúrgico, invitando al lector a centrarse en lo esencial y clavar los ojos en Cristo, que es el autor y consumador de nuestra salvación (cf. Heb 12,2; Ef 2,8-9). Respiran estas páginas un profundo amor al Redentor y a su Esposa, la Iglesia, formada por santos y pecadores, una Iglesia samaritana, una Iglesia evangelizada y evangelizadora, una Iglesia que desea ser fiel a la misión asignada por su divino Fundador, por lo cual se afana por desligarse de la mundanidad, para que su rostro no quede afeado, sino nimbado de la luz que recibe de Aquel que en la Cruz dio supremo testimonio de amor y compasión.

Y es justamente la componente eclesial la que se desarrolla de manera más amplia en la parte final de esta obra, dedicada a glosar el camino del pueblo de Dios peregrino en el mundo, abierto a las interpelaciones que 
le llegan de la sociedad y sus instituciones, que atañen a ricos y pobres, a ancianos y jóvenes, enfermos, personas sin techo $u$ hogar... La Iglesia tiene multitud de interlocutores y no reputa ajeno nada de lo humano, pues no existe para aislarse. Más bien apuesta por el diálogo y el coloquio franco con sus contemporáneos para brindarles, sin aspavientos, el tesoro que a ella la enriquece, y que no es otro que la Palabra de Cristo, fuente de plenitud y de vida auténtica, artífice de paz consumada. En este tercer bloque se abordan también cuestiones de religiosidad popular, tratadas siempre con profundo conocimiento, dada la notable experiencia pastoral del Prelado en este campo.

Concluyendo, este volumen es una variada y rica compilación de criterios y sugerencias para tomar la vida en serio y huir de planteamientos superficiales o anodinos. Para ello, su autor anima continuamente a pasar por este mundo imitando a Jesús, que no se cansó de abrir horizontes de bondad y nos legó como herencia el distintivo de la caridad.

Estas páginas, cuyos destinatarios pueden ser sacerdotes, laicos o consagrados, jóvenes o personas que viven en soledad, sirven de compañía y hacen pensar a los miembros de la Iglesia. Pero no se limitan a ellos. A los que ya forman parte de la familia eclesial, esta publicación los alienta con vehemencia a recordar que el bautismo, puerta que nos otorga la filiación divina y la ciudadanía eclesial, es un sacramento con repercusiones en lo cotidiano, para que no olvidemos que somos hijos de la luz e hijos del día. Por ello hemos de difundir la fragancia de las obras de misericordia, ser oyentes de la Palabra, místicos en medio de la acción, apóstoles y heraldos de la mejor de las noticias: el amor ilimitado de Dios por el hombre, en especial por el postergado y desfavorecido. Él se inclina con ternura hacia cada uno de nosotros. Tiene deseos de vernos a todos unidos como familia. Sueña que esta tierra sea una casa común, en donde nadie se sienta excluido, rezagado u olvidado, sino que sea valorado en su dignidad inviolable. Estas páginas, en fin, por la calidez de sus planteamientos, invitan igualmente a los que no conocen a Cristo ni sintonizan con la Iglesia a no caer en tópicos manidos sobre la vida cristiana ni a quedarse herméticamente cerrados en sus razonamientos, suscitando apertura e invocando el respeto. Lo cual es un gran servicio del autor a muchos que, como los Magos de Oriente, buscan para sus vidas y su entorno una novedad benéfica (cf. Mt 2,1-12).

Fernando Chica Arellano

Observador Permanente de la Santa Sede ante la FAO, el FIDA, y el PMA arellano@libero.it 